\title{
A versión poética de Hes.Op.1-53 por Aquilino Iglesia Alvariño
}

\author{
The Poetic Version of Hes.Op.1-53 by Aquilino Iglesia Alvariño
}

\author{
Amelia Pereiro Pardo \\ Universidade de Santiago de Compostela \\ Departamento de Latín e Grego \\ ameliadelc.pereiro@usc.es
}

[recibido 31/10/2014, aceptado 27/01/2015]

\section{RESUMO}

En 1986 foron publicadas unhas traducións inéditas de Aquilino Iglesia Alvariño, co gallo de celebrarse o Día das Letras Galegas na súa honra. Unha delas correspondía a unha versión poética en lingua galega do comezo do poema Traballos e Días de Hesíodo. A lectura e tradución dos clásicos grecolatinos constituía un dos alicerces da súa poesía. Por esta razón, o obxecto deste traballo é estudar esta versión de Hesíodo para afondar no coñecemento da súa actividade tradutora.

PALABRas ChaVe: Aquilino Iglesia Alvariño, Hesíodo, tradución literaria ao galego, literatura comparativa.

\section{RESUMEN}

En 1986 fueron publicadas unas traducciones inéditas de Aquilino Iglesia Alvariño, con motivo de celebrarse el Día das Letras Galegas en su honor. Una de ellas correspondía a una versión poética en lengua gallega del comienzo del poema Trabajos y Días de Hesíodo. La lectura y traducción de los clásicos grecolatinos constituía uno de los cimientos de su poesía. Por esta razón, el objeto de este trabajo es estudiar esta versión de Hesíodo para profundizar en el conocimiento de su actividad traductora.

PALABRAS CLAVE: Aquilino Iglesia Alvariño, Hesíodo, traducción literaria al gallego, literatura comparativa.

\section{ABSTRACT}

In 1986 some unpublished translations of Aquilino Iglesia Alvariño were edited in view of the celebration of the "Día das Letras Galegas" in his honour. One of them was a Galician poetic version of the beginning of the poem Works and Days of Hesiod. The reading and translation of the Greek and Latin classics was one of the foundations of his poetry. Therefore, the aim of this work is to study this version of Hesiod and to learn more about his translations.

KEY WORDS: Aquilino Iglesia Alvariño, Hesiod, Galician literary translation, comparative literature.

Pereiro Pardo, A. (2015): “A versión poética de Hes.Op.1-53 por Aquilino Iglesia Alvariño”, Madrygal (Madr.), 18, Núm. Especial: 243-253.

SUMARIO: 1. Introdución: presuposto metodolóxico. 2. Datos biográficos. Reflexión sobre a tradución. 3. A tradución dos vv. 1-53 de Traballos e Días. 4. As dúas Érides, vv. 11-26. 5. Conclusións. 6. Referencias bibliográficas. 


\section{INTRODUCIÓN: PRESUPOSTO ME- TODOLÓXICO}

A tradución non é un simple traballo de substitución, senón unha operación creativa caracterizada por tres trazos esenciais: é un acto de comunicación, é unha operación entre textos e é un acto cognitivo. Esta tripla caracterización leva a Hurtado (2001: 41) a propoñer definir a tradución coma "un proceso interpretativo y comunicativo consistente en la reformulación de un texto con los medios de otra lengua que se desarrolla en un contexto social y con una finalidad determinada".

A tradución como proceso comprende polo menos dúas linguas distintas coas súas respectivas culturas, unha variedade de dominios de definición e a problemática intervención dun tradutor (Hewson e Martin 1991: 3). Este non é un axente cultural neutro, senón que, no momento que escolle e transfire un texto ao seu sistema cultural, proporciónalle nova vida -é o que Lefevere (2003: 234-242) denomina reescritura-; e converte a actividade tradutora nunha actividade subxectiva que pode xogar un papel cultural na sociedade receptora ao introducir novos conceptos, novos xéneros e novos mecanismos, sobre todo naquelas sociedades en que era necesario fomentar o seu sistema literario, como era o caso na época do noso autor.

Polo tanto, todo estudo e valoración dunha tradución necesita coñecer a figura do tradutor: saber quen, que tipo de textos traduciu e por que, en que época viviu e que criterios o guían no seu traballo (reproducir a forma da mensaxe ou buscar a resposta do lector a esa mensaxe, a súa teoría da tradución, a súa actitude cara á lingua). Desde esta formulación metodolóxica valorarase a versión que Iglesia Alvariño fixo dos cincuenta e tres primeiros versos de Traballos e Días do poeta grego Hesíodo.

\section{DATOS BIOGRÁFICOS. REFLEXIÓNS SOBRE A TRADUCIÓN}

Aquilino Iglesia Alvariño(Seivane-Abadín, 1909) cursou estudos no Seminario de Mondoñedo, onde iniciou a súa actividade poética en lingua galega. Neses anos foi un gran lector, sobre todo de poesía, na que cabe salientar a súa achega aos clásicos Virxilio, Ovidio e Horacio, grazas á súa fonda formación na lingua latina. No verán de 1931, tras superar brillantemente o terceiro curso de Sagrada Teoloxía, interrompe os seus estudos no Seminario que abandonará en 1934 tras establecerse como profesor no Colexio León XIII en Vilagarcía de Arousa. Desde entón compaxinará a docencia coa poesía e os estudos filolóxicos. En 1944 obtén a Licenciatura en Filosofía e Letras pola Universidade de Santiago de Compostela. Elixido membro numerario da Real Academia Galega en 1947, dous anos despois, en 1949 , le o seu discurso de ingreso titulado A lengua dos poetas do norte de Lugo. Nese mesmo ano obtén a Cátedra de Latín. O seu primeiro destino foi o Instituto Feminino de Lugo, de onde pasou ao Instituto de Pontevedra, cidade na que residirá durante cinco anos. En 1954 trasládase ao Instituto Rosalía de Castro de Santiago de Compostela. Nesta cidade morrerá no mes de xullo de ano $1961^{1}$.

A súa actividade literaria desenvólvese no marco da Xeración de 1936, que foi a ponte que enlazou a brillante actividade cultural das décadas anteriores á Guerra Civil coa Xeración da Posguerra. Iglesia Alvariño foi un bo coñecedor das correntes literarias do seu tempo como da obra dos clásicos europeos e grecolatinos, polo que a súa obra conxuga clasicismo e modernidade, sen faltar nunca á súa propia identidade. Pero o seu apego ao mundo clásico fixo que fora interpretado coma persoa allea ás modas literarias, pois para el a poesía non é unha moda senón intentar conseguir un modo propio (Rodríguez 1994: 397).

${ }^{1}$ Para unha información biográfica máis detallada, véxase Iglesia Alvariño (2011: 9-26, 27-53 e 141162), Rodríguez (1994: 21-48) e Fraguas Fraguas (1986: 7-9). 
Na procura dese "modo propio" ocupou tempo en verter á súa lingua materna unha significativa selección de textos grecolatinos. Aquilino tiña unhas ideas moi claras de como encarar esa actividade e púxoas por escrito.

O dez de febreiro de $1948^{2}$, no diario compostelán La Noche e baixo as súas iniciais A.I.A., publicou por primeira vez unha tradución ao galego feita na súa época de estudante (Iglesia Alvariño 1948a: 3). Trátase da versión en prosa dunha pasaxe da Ilíada (8.261-334), na que Homero describe un combate de Teucro Telamón contra os troianos. O Prof. Rabanal (1948: 4) ${ }^{3}$ na súa columna habitual do mesmo diario gabou dous días máis tarde a dita versión, pero discrepaba que se dixera do heroe, cando era conducido ferido cara ao campamento aqueo, que "arquexaba coma un boi". Pois se ben esta interpretación

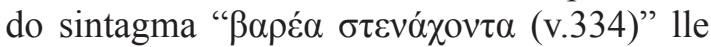
parecía excelente desde o punto de vista da lingua termo ("Sencillamente estupendo. Más homérico que el propio Homero"), oponlle reparos filolóxicos e suxire a A.I.A. outra tradución: “(...) lloraba o dejaba escapar del pecho herido una profunda quejumbre?". Rabanal no final do seu artigo apela a Iglesia Alvariño, como amigo dos dous e bo coñecedor de ambas as dúas linguas, o grego e o galego, a que manifeste o seu parecer.

Iglesia Alvariño (1948b), na súa contestación de meses máis tarde no mesmo xornal, expón sobre a tradución uns criterios que subscribiría, sen dúbida, a Tradutoloxía actual. Empeza recoñecendo as dificultades que entraña a tradución literaria, pero observa que as traducións correntes nas que se traducen as palabras, categoría por categoría e cargadas de notas, tal vez consigan levarnos a través dun mundo estraño e arqueolóxico, pero nunca conservarán "a armonía musical en que las palabras se equilibran mágicamente en compases de silencios" (1948b: 4). Pois "la tradución está en la penetración de los silencios sobre todo, de lo que no se dice, pero que es ritmo y número de lo que decimos" (id.), que é o que produce emoción cando se le unha composición. Afirma que unha tradución que se limite ao texto será o famoso "tapiz del revés" e recoñece que o tradutor nunca poderá repetir a mesma resonancia do texto orixinal, pero que iso non importa, pois o que vale é crear un texto na lingua de chegada que conserve o sentido e que produza tanta emoción como o orixinal: o caso é "non matar as palabras" e manter "os silencios". Está seguro Aquilino de que a primeira tradución que lle veu á mente ao aprendiz de tradutor, A.I.A., foi o "sabido «daba grandes suspiros, suspiraba profundamente»", que é "«un desir llano» aceptable, pero no una traducción"; e, por iso, "buscando y rebuscando entre los decires gallegos" A.I.A. escolleu a expresión de maior resonancia homérica. Remata dicindo que "cada pueblo tiene su traducción, cada generación la suya. Y cada espíritu enciende también su llama

${ }^{2}$ Esta publicación, segundo di na introdución, é en honor de Portela Paz (Iglesia Alvariño 1948a). Portela Paz, co obxecto de render homenaxe á vila de Pontevedra, editara en 1947 un libro de artigos baixo o título Pontevedra, boa vila. O segundo traballo "Teucro de paso por aquí" é da autoría de Aquilino, que revela cal foi o verdadeiro papel de Teucro Telamonio na fundación desa vila. No ano anterior, en 1947, publicara Cómaros Verdes, o seu primeiro libro de poemas tras a paréntese que supuxera para el o período que seguiu á Guerra Civil. Nunha época na que se chegou incluso a multar a correspondencia en galego, Iglesia Alvariño empeza a publicar poesías en galego desde 1945 nalgunhas revistas (Iglesia Alvariño 2011: 49). No seu labor tradutor anterior só publicara unha versión ao castelán dun poema de Horacio (Iglesia Alvariño 1936) e animara a dous alumnos seus a publicaren a tradución ao galego de poemas latinos e ingleses, prologada por el (Porto González e Alvés 1936). É interesante sinalar que a última tradución ao galego dun texto grego remóntase a unha tradución dos versos 96-137 dos Fenómenos de Arato polo autor santiagués Barcia Caballero (Amado Rodríguez 2010: 477).

${ }^{3}$ Manuel Rabanal era naquela época catedrático de Grego no Instituto compostelán Rosalía de Castro e profesor na Facultade de Filosofía e Letras da Universidade de Santiago de Compostela. 
nueva" (1948b: 4). Pódese deducir, polo tanto, nesta alegación que para Iglesia Alvariño a tradución non era un simple traspaso dun código lingüístico a outro código lingüístico, senón que era un acto de natureza comunicativa, transcultural, pois vai dirixido a uns destinatarios que viven nun contexto sociocultural determinado. A tradución, polo tanto, ten que manter a intención comunicativa do texto de partida, pero é xa un texto diferente inmerso noutro sistema cultural e lingüístico.

Tres anos máis tarde saíu do prelo a súa tradución en verso dos Carmina de Horacio ${ }^{4}$. No prólogo (Iglesia Alvariño 1951: IX-XII) volve incidir no feito de que non é un filólogo que quere facer revivir os poemas orixinais, polo que advirte que da súa lectura de Horacio xurdiron non propiamente traducións, imitacións ou glosas, senón "poemas nacidos a beira dos Carmina". E desenvolve por extenso unha idea xa apuntada no artigo do periódico La Noche: tratar de mudar a poética dominante no sistema literario galego da súa época, que tendía a callar na linguaxe e nas fórmulas fixas do Cancioneiro medieval. O que intentará coas traducións dos clásicos será "anchear os vellos vocabularios, a vella sintaxis, os vellos temas poéticos" (Iglesia Alvariño 1951: x), é dicir, introducir novos conceptos, novos xéneros e mecanismos - proponse actuar así como un axente cultural con poder de transformación. Neste mesmo prólogo presenta outros datos moi valiosos, como o da súa elección pola variante do galego oriental, argumentando que é a do seu falar e que non hai un módulo literario que se impoña con forza. Expón tamén a súa opinión de que o rexistro literario do galego se ten que nutrir da lingua que se fala nos campos e ribeiras; por ese motivo afástase das "feituras literarias anovadas e das xa mortas" (Iglesia Alvariño 1951: X-XI), e escolle, as máis das veces, as formas vivas aínda que sexan castelanismos. Remata o prólogo sinalando as tres edicións sobre as que baseou a súa tradución: a súa formación obrígalle a ser moi exquisito na escolla das mellores edicións do texto orixe.

Esta tradución dos Carmina de Horacio suscitou reaccións diversas, aínda que coincidentes no recoñecemento unánime da riqueza e aire fresco que achegaba á lingua poética. Salvador Lorenzana (1963: 40) e Carballo Calero (1975²/ 19813: 747-748) sancionan o labor de Iglesia Alvariño fronte a outros eruditos. Quintela Ferreiro (1964: 80) considera que o noso poeta logrou plenamente o seu empeño de dar maior flexibilidade e riqueza ao galego poético, o que explica as liberdades tomadas, pero non lle gusta o ton excesivamente rústico.

En 1960 no Suplemento da revista da Sociedade Española de Estudos Clásicos - canle diferente das utilizadas nas dúas traducións anteriores- publica a súa edición do poema latino Pervigilium Veneris coa súa versión en galego. Realiza así un traballo filolóxico, aínda que, como advirte no prólogo, na versión se serve do galego falado no interior de Galicia, cos inevitables cultismos (cisnes, claustro, ninfas, etc.) e as formas anovadas (deus, deusa, dona, doncela e raíña), porque na lingua falada están castelanizadas. O uso das formas anovadas é probable que sexa unha concesión ao contexto da publicación. Informa, ademais, que renuncia a verter en tetrámetros galegos imposibles o ritmo dos tetrámetros trocaicos latinos, pero que si mantivo o seu sistema de aliteracións, anáforas e asonancias característicos (Iglesia Alvariño 1960a: 336). Continúa fiel, polo tanto, ás súas ideas da lingua e da importancia de manter a "emoción".

Nestes tres textos maniféstase a modernidade das ideas do noso poeta: a súa negativa a que a tradución sexa un simple transvase de palabras dunha lingua a outra; a súa defensa de que a tradución é xa outro texto e outra literatura e non debe mirar por revivir o texto orixe, senón a "emoción", valéndose sempre da

\footnotetext{
${ }^{4}$ En 1949 aparecen en La Noche traducións súas da obra do poeta inglés John Masefield, e en 1950 a súa versión galega en verso do Galliciense Carmen de Venancio Fortunato. Sen prólogo e só informa na p. 3 que é un "Tributo Pontevedrés al Congreso Bracarense del XIV Centenario de San Martín de Dume".
} 
súa formación filolóxica na escolla das mellores edicións do texto orixe; a intuición de que hai tantas traducións dun texto como persoas, xeracións e sociedades - polo tanto, da importancia do contexto social e histórico-; e, por último, a plena consciencia de que todo tradutor pode influír na evolución ou no cambio do sistema literario, no momento en que pensa que as versións dos clásicos ao galego poden ser o eixo transmisor de novos modos lingüísticos e temas poéticos como xa sucedera na maioría das literaturas europeas. Así pois, coa finalidade de privilexiar a cultura de chegada, pero sempre enfrontándose ao texto orixe desde a súa formación filolóxica, encarou o seu labor tradutor ${ }^{5}$.

Entre 1960 e 1961, os dous últimos anos da súa vida, realiza unha intensa actividade de publicación da súa obra. Ademais da xa citada edición do Pervigilium Veneris, en 1960 publica De día a día ${ }^{6}$ no que a maioría dos poemas aparecen precedidos por citas traducidas de autores do séculos XIX e XX e sobre todo dos poetas Sófocles, Lucrecio e Virxilio:

todas as citas (...) xogan un papel guía na lectura temática dos poemas do libro (...); configuran, pois, un deseño editorial significativo e nada caprichoso, como nunha primeira achega ao poemario se poidese sospeitar: unha compenetración total entre cita e texto na súa andadura temática. (Rodríguez 1994: 270)

O seguinte poemario, Lanza de soledá (1961), é "un libro de formación clásica, de recursos clásicos e soamente tocado polo propósito moderno de, como dixo Cunqueiro, «botar viño novo en odres vellos»" (Lorenzo Baleirón 1985: 166). A maioría dos poemas levan citas coa mesma funcionalidade que en De día a día, nas que predominan tamén os clásicos grecolatinos. A terceira é última parte do libro leva como título "De remate". Esta sección está constituída por un único poema en hendecasílabos brancos "A despedida de Áyax", que se corresponde cos vv. 845-865 da traxedia Áiax de Sófocles, e así o sinala o autor ao pé do poema. Son as derradeiras palabras que pronuncia o heroe Telamonio, antes de morrer, ao despedirse dos seus pais e da súa terra e que o poeta de Seivane fai súas como despedida poética e vital (Pereiro Pardo 2002: 1745-1746).

A súa última obra poética, publicada en vida, Nenias, é unha homenaxe aos seus poetas con pezas que van desde 1946 ata 1961 . O poemario está dividido en dúas partes: a primeira, “Terra do corazón" (anos 1947-1961), está dedicada aos poetas galegos; e a segunda, "Vento da alma" (anos 1946-1961), aos poetas estranxeiros. Comeza esta segunda parte co fermoso poema "Polos vellos poetas que foron" datado en 1946, no que o motivo das Idades do Home, que cantou Hesíodo no seu poema Traballos e Días, conforma o marco no que lle rende homenaxe a "toda unha familia poética" que vai desde os poetas grecolatinos ata os máis próximos ao seu tempo (Rodríguez 1999: 390-391, Moralejo Álvarez 1992: 102); e continúa con dous poemas que celebran a Catulo (1947) e a Tibulo (1947) respectivamente ${ }^{7}$.

En 1961 publica As meigas, versión galega do idilio II de Teócrito, na Appendix Poetica da revista Euphrosyne baixo o apartado de Carmina Gallaeca e Lusitana. Non presenta ningunha nota filolóxica nin prólogo. Tras a súa morte, foi publicada en 1962 a súa versión da Aulularia de Plauto, que leva coma título $A$ comedia da oliña.

\section{A TRADUCIÓN DOS VV. 1-53 DE TRABALLOS E DÍAS}

Díaz y Díaz publicou na revista Grial en 1986 unhas traducións inéditas de Aquilino Iglesia, co gallo de celebrarse o Día das Letras

En 1958 colabora nun libro de homenaxe a Otero Pedrayo co poema dramático "Segunda vocación de Adrián Silva", que é unha recreación intertextual de pasaxes das Bacantes de Eurípides (Amado Rodríguez 2002).

${ }^{6}$ Neste libro recompilou poemas, a maioría deles datados, que van desde a década dos 30 ata 1960.

${ }^{7}$ Estes tres poemas apareceran xa na terceira parte de Cómaros Verdes. 
Galegas en honor do poeta de Seivane. Infórmanos o Prof. Díaz na introdución que a familia do escritor lle entregara moitos papeis do escritor con notas e informacións arranxadas para as investigacións que estaba a realizar; e entre eses papeis atopou "uns textos, que poideran decirse en limpo, con catro traducións de latín e unha do grego, ao meu ver inéditas" (Díaz y Díaz 1986: 194). Polo que di nunha nota dedúcese que estes estaban mecanografados (ibid. 193-194 e n. 1). A orde de publicación dos inéditos é a seguinte: primeiro van os que corresponden aos catro poetas latinos, pero, como o poema de Tibulo consta de versión en verso e en prosa, as traducións van numeradas desde $o \mathrm{n}^{\mathrm{o}} 1$ ata $\mathrm{o} \mathrm{n}^{\mathrm{o}} 5$. Correspóndelle, polo tanto, ao texto grego o lugar $\mathrm{n}^{\circ} 6$. Advírtese que se publica este texto coas rectificacións e variantes que fixo Iglesia Alvariño e que van no seu correspondente verso en notas a rodapé (Díaz y Díaz 1986: 196). A tradución leva coma título Hesíodo: "Os Traballos e os Días", e debaixo del na marxe esquerda un lugar e unha data (Barcelona, 1-V-61), cunha nota do Prof. Díaz que indica que así estaba no orixinal (1986: 201 n. 1).

O texto galego corresponde realmente á tradución dos cincuenta e tres primeiros versos do poema grego Traballos e Días. Estamos ante un traballo incompleto ${ }^{8}$ que probablemente a morte do poeta impediu a súa finalización. $\mathrm{O}$ poema grego consta de 828 hexámetros dactílicos e é obra do poeta Hesíodo, que puido vivir na segunda metade do século VIII a.C. ou na primeira metade do século VII a.C. O título, non orixinal do autor senón posterior, corresponde propiamente a dúas seccións do poema: os Traballos (vv. 286-694), onde se informa de como dispoñer os traballos agrícolas de acordo cos ciclos das estacións e da mellor época para a navegación, e os Días (vv. 765828), que é un calendario sobre os días do mes que son faustos e infaustos para o traballo agrícola e para as restantes actividades. Este poema, xunto ca Teogonía, chegou ata os nosos días a través de manuscritos bizantinos, o que proba unha tradición ininterrompida e de gran difusión na Antigüidade (Rodríguez Adrados 2008: 66-68).

Como ben di o mesmo autor (2008: 67) este poema ofrece por primeira vez un pequeno cadro familiar. Hesíodo, fillo dun emigrante de Asia, pertence a unha familia de labregos que só traballando duramente "ergue para riba a facenda", en tradución de Aquilino Iglesia do v. 23 (Díaz y Díaz 1986: 202), e que depende duns "reis" que poden abusar del. Este poema grego canta un tema universal e atraente para o poeta de Seivane, pois sempre estivo moi unido á súa raigame labrega (Fernández del Riego 2003: 15). De feito, pódese rastrexar na súa obra poética a súa lectura de Hesíodo. O poema "Polos vellos poetas que foron", coma xa se indicou, ten como referente o mito das Idades do Home (Hes.Op.106-201). No prólogo de Lanza de Soledá fala das persoas desesperadas das que "Deles é o baduar da noite e o rilar da voutre que non ten cabo" (Iglesia Alvariño 1961a: 13). Esta "voutre" remítenos a Prometeo (Rodríguez 1994: 322), cuxo mito nolo relata Hesíodo na Teogonía e nos Traballos e Días. E no libro De día a día, no poema, sen data, titulado "Epístola a D. Ramón Otero Pedrayo", establece unha fermosa comparación entre a uniformidade dos maraños que deixan os gadañeiros trala sega e

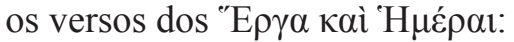

\footnotetext{
${ }^{8}$ Díaz e Díaz (1986: 196) observa que: “Aínda incompleta e inacabada, ten de seu moito interés polo esforzo que supón no traductor", e Alonso Montero (1986: 14) informa que: "Nunha bibliografía de urxencia que redactou para min Aquilino, Iglesia Ferreiros, consígnase: “Os traballos e os días. -Hesíodo. -Inédito e inacabado".

${ }^{9}$ Este poema é unha versión da carta-poema datada o 26 do mes da sega de 1951 e que Aquilino Iglesia enviara en agradecemento a Ramón Otero Pedrayo (Alonso Montero 1986: 168-170); de feito, os versos comentados non aparecen no orixinal. Otero Pedrayo nun artigo publicado o 10 de xuño de 1951 no diario compostelán La Noche acollía con ledicia a pronta saída do Horacio galego do poeta de Seivane.
} 
Os menceres despértanse coa xorda canción dos gadañeiros. Atrás deles

queda a herba en maraños ben medidos, de braza en braza, coma os versos dondos e redondos dos "Erga kai jemerai". (vv.40-44)

Os dez primeiros versos corresponden ao proemio, no que Hesíodo comeza exhortando ás Musas de Pieria en Macedonia a que celebren a Zeus. Continúa cun eloxio do deus e cunha petición para que restableza as leis divinas mediante a súa xustiza. Remata o proemio dicindo que vai cantar catro verdades ao seu irmán Perses. Nos seguintes 16 versos cumpre o prometido e avisa a Perses da importancia da xustiza de Zeus e do traballo a través do mito das dúas Érides ou Discordias - unha mala que incita á loita e outra boa que incita á emulación polo traballo. Na pasaxe seguinte (vv. 2752) Hesíodo increpa o seu irmán Perses para que non intente preitear con el pola herdanza do seu pai. Fálalle da dificultade da vida dos homes e da necesidade do traballo e conta como Prometeo roubou o fogo a Zeus. A tradución remata no verso 53 cando Zeus "cheo de coraxe" se encara con Prometeo.

Os primeiros cincuenta e tres versos do orixinal corresponden cos cincuenta e tres versos da tradución, cuxa pausa versal coincide, salvo excepcións ${ }^{10}$, coa unidade de sentido do verso orixinal. Reprodúcese o ritmo do hexámetro dactílico coa tirada rítmica de heptadecasílabos dactílicos con acento rítmico do tipo 1.4.7.10.13.16 ${ }^{11}$. Os versos 6, 7, 23, $31 \mathrm{e}$ 37 son octodecasílabos dactílicos con acentos rítmicos en 2.5.8.11.14.17. Os versos 26 e 52 están compostos cada un de 20 sílabas. O primeiro, con claro ritmo dactílico, remata coa pasaxe das Érides (“Tén así o póbre do póbre cubíza e o cégo do cégo cantór"), e o segundo verso conta como Prometeo lle roubou o fogo a Zeus ("drento dunha cana de sabugueiro, enganando a Zeus que lostrega"). O v. 21 pode ser un hexadecasílabo ("Bota o trafego de menos un cando mira pra outro"): 8 (1.4.7) + 8 (1.4.7). E, finalmente, o v. 48 ("porque o enganou Prometéu retorto") é un hendecasílabo dactílico que, aínda que unha nota do autor di "Repetir (?)", pode intensificar o porqué de agochar Zeus o fogo aos homes.

Non se pode saber se este anisosilabismo tería sido corrixido no caso de ser publicada esta versión polo seu autor. Na tradución do II Idilio de Teócrito, reproduciu tamén os hexámetros dactílicos do orixinal nunha tirada de heptadecasílabos dactílicos con algún octodecasílabo dactílico.

Non hai ningunha información respecto do texto grego utilizado, pero partindo da súa práctica habitual ben se pode asegurar que se serviría de boas edicións. Estes cincuenta e tres primeiros versos non presentan moitos problemas de lectura, pero baseándonos na tradución do verso 21, "bota o trafego de menos un cando mira pra outro", e a do verso 37, "Ben certo que a herencia partimos; mais ti arrapiñando á barullo", probablemente seguiu a lectura da edición da Loeb Classical Library realizada por Evelyn-White para o

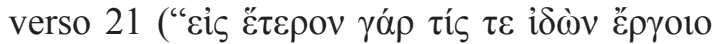
$\chi \alpha \tau^{\prime} \zeta \zeta \varepsilon$ ", que tamén ofrece P. Mazón, fronte a outras edicións que presentan a lectura "' $\delta \varepsilon v$

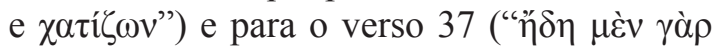
$\kappa \lambda \tilde{\eta} \rho \circ v^{2} \delta \alpha \sigma \sigma \alpha ́ \mu \varepsilon \theta^{\prime}, \dot{\alpha} \lambda \lambda \grave{\alpha} \tau \grave{\alpha} \pi \mathrm{o} \lambda \lambda \dot{\alpha}$ ”, fronte

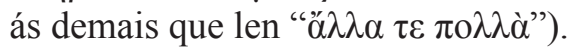

\section{AS DÚAS ÉRIDES, VV. 11-26 ${ }^{12}$}

Escóllese a pasaxe das dúas Érides para amosar uns trazos da versión de Iglesia Alvariño:

\footnotetext{
${ }^{10}$ Nos vv. 4 e 16 engade respectivamente as palabras "son" e "fórzaos", que corresponden aos versos precedentes. No v. 37, "arrapiñando" pertence ao verso seguinte.

${ }^{11} \mathrm{O}$ v. 21 pode ser un hexadecasílabo "Bota o trafego de menos un cando mira pra outro": $8(1.4 .7)+$ 8 (1.4.7).

${ }^{12}$ Reprodúcese aquí o texto de Iglesia Alvariño xunto co texto grego da edición de Evelyn-White.
} 


\section{As duas loitas}

No houbo unha sola ralea de loitas. Por riba da terra

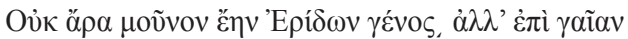
tópanse dúas: á unha, o que a conoza, ha laudala.

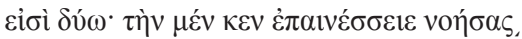
A outra, ai fó! O seu sentir teñen de cada seu lado.

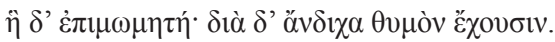

Esta é a que ceba na guerra e nas leas que en mal se rematan,

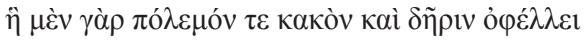

15 ela e malina. Ninguén dos que viven a ama. Con todo

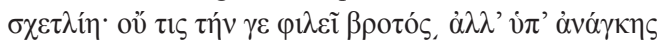
fórzaos mandado dos dioses á adorar esta loita tan dura.

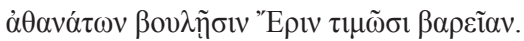

Foi a primeira filla a outra da noite pechada.

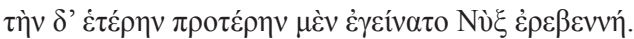
Púxoa o Cronida do alto, que vive nos pazos do aire

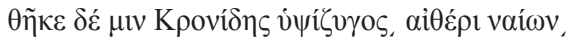
xunta ás raíces da terra e é do mellor para os homes.

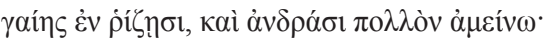

20 Ela envereda ó traballo ó desganzado, que seña.

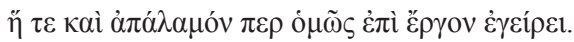
Bota o trafego de menos un cando mira pra outro

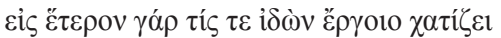
rico que boura labrando, ou ben espetando bacelos,

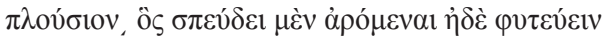
e ergue pra riba a facenda. Cubiza o veciño o vecino,

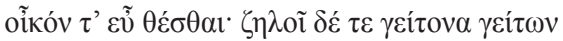
cando se afana por tere. Ben boa é esta loita pra os homes.

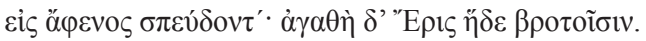

25 Rifa asi o oleiro co oleiro, e rifa o ubreiro co ubreiro.

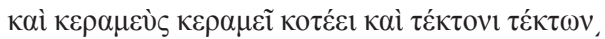
Ten asi o pobre do pobre cubiza e o cego do cego cantor.

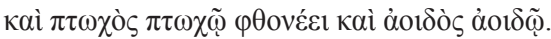

Cada un dos versos galegos coincide co seu correspondente hexámetro grego, coa excepción do v. 16 (vid. nota n. 10). Os quince versos son heptadecasílabos dactílicos, excepto o v. 23 que é un octodecasílabo dactílico e o verso 26 que cerra a pasaxe que consta de 20 sílabas, pero mantén o ritmo dactílico como o resto. Reprodúcese, polo tanto, na versión galega o ritmo dactílico do orixinal. Cando corresponde mantén o encabalgamento (vv. 12, 22). Pero no verso 15 non o conserva, pois traduce o adxectivo nunha oración copulativa independente.

Iglesia Alvariño na marxe dereita intitula a pasaxe como "As dúas loitas". Evita o cultismo de Érides e talvez escolle o termo de "Loita" polo que pode ter de esforzo positivo para conseguir algún ben, a diferenza da tradución habitual de "Discordia". No verso 11

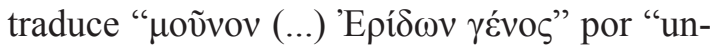
ha sola ralea de loitas". O termo "ralea" ten un valor despectivo que non posúe a palabra grega que significa 'liñaxe, estirpe'. Pode que teña presente que na Teogonía (v. 226) Hesíodo fala dunha soa Éride e que esta é " $\sigma \tau \gamma \gamma \varepsilon \rho \eta$ " ("odiosa"). É interesante deterse no versos 12 e 13, nos que Hesíodo describe a reacción que cada unha produce nos homes. Da Éride positiva di: “(...) á unha o que a conoza, ha laudala". Iglesia Alvariño reflicte ben o verso grego coa ampliación lingüística "o que a conoza"

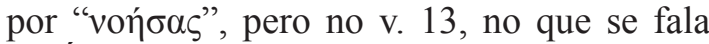
da Éride negativa, substitúe a oración nominal “ฑ $\delta$ ' $\dot{\pi} \pi \mu \omega \mu \eta \tau \eta$ ”, cuxa tradución literal é "a outra é censurable", pola interxección "ai, fó!" - o cambio da función ilocutiva reforza a reacción negativa que debe producir esta Éride nos homes.

No v. 17 mantense o sentido pero non a orde de palabras nin a sintaxe do grego. É interesante resaltar a tradución de "Nv̀ $\xi$ é $\rho \beta \varepsilon v v \eta '$ ", literalmente "Noite tenebrosa, sombría", pola expresión "Noite pechada". No v. 24 o adxec-

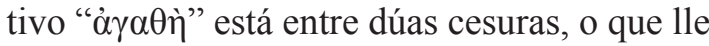
da unha énfase especial; Iglesia Alvariño mantén ese valor enfático conservando a posición central do adxectivo e traducindo "ben boa".

Remata esta pasaxe cos versos 25 e 26: no primeiro muda o quiasmo do orixinal polo paralelismo sintáctico, mentres que no verso 26 mantén o paralelismo do verso grego. Traduce o verbo " $\varphi \theta$ ovéєı", literalmente "envexar", por "cubizar", verbo que ten quizais un sentido non tan negativo como o verbo orixinal. Ao

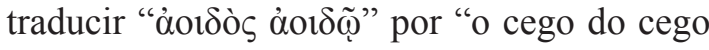
cantor", co adxectivo "cantor", é probable que aluda a Homero, o cantor cego segundo a tradición.

\section{CONCLUSIÓNS}

Así pois, pódese concluír, por unha parte, que Iglesia Alvariño enfoca sempre a súa tarefa de tradutor á lingua termo, o galego, pero partindo de boas edicións do texto orixe. Non intenta unha tradución filolóxica, pero ten unha boa formación filolóxica que se reflicte 
no seu traballo. Doutra parte, reúne na súa persoa a figura de tradutor axente e tradutor iniciador, pois escolle os textos que lle interesan. Por último, a lectura dos clásicos grecolatinos alimenta a súa propia poesía ao mesmo tempo que lle axuda, dado o seu compromiso vital coa lingua galega, a introducir novos temas, novos modos na poesía galega.

\section{REFERENCIAS BIBLIOGRÁFICAS}

Alonso Montero, Xesús (1962): “Aquilino Iglesia Alvariño, traductor de textos latinos y griegos”, Estudios Clásicos 6, pp. 582-583.

(1986): Aquilino Iglesia Alvariño. Poesía galega completa. Vigo: Xerais.

Amado Rodríguez, María Teresa (2002): “Ecos dionisíacos en la 'Segunda vocación de Adrián Silva’ de Aquilino Iglesia Alvariño”, en J. M. Maestre Maestre, J. Pascual Barea e L. Charlo Brea (eds.), Actas del III Congreso Internacional de Humanismo y Pervivencia del mundo clásico. Homenaje a Antonio Fontán. Madrid: Ediciones del laberinto, vol. 4, pp. 1785-1798.

(2010): "La traducción de los clásicos en Galicia", en F. García Jurado, R. González Delgado e M. González González (eds.), J. C. Mainer (pro.), La historia de la literatura grecolatina durante la Edad de Plata de la cultura española (1968-1936). Málaga: Universidad, pp. 461-485.

Carballo Calero, Ricardo (19813 $\left.\left[1975^{2}\right]\right)$ : Historia da literatura galega contemporánea. Vigo: Galaxia.

DíAz y DíAz, Manuel C. (1986): "Unhas traduccións inéditas de Aquilino Iglesia Alvariño", Grial. Revista galega de cultura 24, pp. 193-203.

Evelyn-White, Hugh G. (1936², reimpr. 1954): Hesiod. The Homeric Hymns and Homerica. Cambridge, Massachusetts / London: Harvard University Press / William Heinemann Ltd.

FernÁNDEZ DEL Riego, Francisco (2003): "Co poeta na súa montaña”, Culturas. La Voz de Galicia 11/10/2003, p. 15.

Fraguas Fraguas, Antonio (1986): Aquilino Iglesia Alvariño. Vida e obra. Escolma de textos. A Coruña: Real Academia Gallega.

Hewson, Lance e Jacky Martin (1991): Redefining Translation. The Variational Approach. London / New York: Routledge.

Hurtado Albir, Amparo (2001): Traducción y Traductología. Introducción a la Traductología. Madrid: Cátedra.

Iglesia Alvariño, Aquilino (1936): La canción del siglo de Horacio: Versión que se hace para la conmemoración del bimilenario del Natal de Augusto. Vilagarcía de Arousa: Tipografía José Paz Gómez.

[asinado A.I.A.] (1948a): “«Fundote Teucro valiente». Semblanza do caporal de homes e de xentes que arribou a Moureira. Arquexaba coma un boi", La Noche: único diario de la tarde de Galicia 10/02/1948, p. 3.

(1948b): "Traduttore, traditore", La Noche: único diario de la tarde de Galicia 13/08/1948, pp. 4-2.

(1950): Venantii Fortunati Galliciense Carmen. Versión galega. Pontevedra: Gráficas Torres [4 Ventos ou Quatro Ventos: revista lusíada de literatura e arte 1, 1954, pp. 5-8]. 
(1951): Q. Horatii Flacci Carmina. Santiago de Compostela: CSIC / Instituto Padre Sarmiento de Estudios Gallegos.

(1958): "Segunda vocación de Adrián Silva", Ramón Otero Pedrayo: a súa vida e a súa obra: Homaxe da Galicia Universal. Caracas: Centro Galego, pp. 91-95.

(1960a): "Pervigilium Veneris: A Vixilia de Venus", Suplemento de Estudios Clásicos 15 , pp. 335-343.

(1960b): De día a día: poesías. Vilagarcía de Arousa: Celta, D. L.

(1961a): Lanza de Soledá. Ourense: La Edición Comercial.

(1961b): Nenias. Vigo: Salnés.

(1961c): "O Segundo Idilio de Teócrito As Meigas. Versión galega en verso", Euphrosyne 3, pp. 569-574.

(1962): A comedia da oliña. Aulularia de T. M. Plauto. Vigo: Galaxia.

(2011): “Autobiografía", "Nota editoral” e "Documentos", Poemas Castellanos. Seivane: Ediciós A Pedrosa, pp. 9-26, 27-53 e 141-162.

Lefevere, André (1985): "Why Waste our Time on Rewrites? The Trouble with Interpretation and the Role of Rewriting in an Alternative Paradigm", en Th. Hermans (ed.), The Manipulation of Literature. Studies in Literary Translation. Londres / Sydney: Croom Helm, pp. 215-243.

LorenzanA, Salvador (pseudónimo de Francisco Fernández del Riego) (1963): "Iglesia Alvariño: poeta e humanista", Grial. Revista galega de cultura 1, pp. 28-42.

LORENZO BALEIRón, Eusebio (1985): “Tradición e modernidade na obra poética en galego de Aquilino Iglesia Alvariño", Grial. Revista galega de cultura 23, pp. 161-170.

Mazon, Paul (1928): Hésiode. Téogonie-Les Travaus et les Jours-Le Bouclier. Paris: Les Belles Lettres.

Moralejo Álvarez, Juan José (1992): "Variantes textuais nun poema de Cómaros verdes de Aquilino Iglesia Alvariño”, Boletín Galego de Literatura 7, pp. 97-102.

Otero Pedrayo, Ramón (1973): “O Horacio galego de Iglesia Alvariño”, en Obras selectas: Parladoiro. Artículos. Vigo: Galaxia, pp. 261-263.

Pereiro PArdo, Amelia (2002): “Aquilino Iglesia Alvariño, traductor de textos griegos al gallego", en J. M. Maestre Maestre, J. Pascual Barea e L. Charlo Brea (eds.), Actas del III Congreso Internacional de Humanismo y Pervivencia del mundo clásico. Homenaje a Antonio Fontán. Madrid: Ediciones del laberinto, vol. 4, pp. 1739-1748.

(2006): “A traducción do Idilio II de Teócrito polo poeta Aquilino Iglesia Alvariño”, en V. Soares Pereira e A. L. Curado (org.), A Antiguidade Clássica e nós. Herança e identidade cultural. Actas. Braga: Universidade do Minho / Centro de Estudos Humanísticos, pp. 481487.

Portela Paz, Agustín (1947): Pontevedra, boa vila. Pontevedra: Gráficas Torres.

Porto González, J. e Armenio Alves (1936): Traducións, Ovidio, Virxilio, Francis James. Vilagarcía de Arousa: Imprenta i-Encuadernación de Bendaña e Paz (Coleición Renacencia 13).

Quintela Ferreiro, Luis José (1964): “Una traducción de Horacio”, en Aspectos económicos y jurídicos de Galicia. Vigo: Galaxia, pp. 80-82. 
Rabanal Álvarez, Manuel (1948): “Arquexaba coma un boi (Coloquio con Iglesia Alvariño en torno a "Iliad.", VIII, 334)", La Noche: único diario de la tarde de Galicia 12/02/1948, p. 4 ['Nebulosas'y otros escritos. Santiago de Compostela: Editorial Compostela, 1992, pp. 3334].

Rodríguez, Luciano (1994): A poesía de Aquilino Iglesia Alvariño. Lugo: Deputación Provincial de Lugo.

Rodríguez Adrados, F. (20084 [1988]): "Hesíodo", en J. A. López Férez, Historia de la literatura griega. Madrid: Cátedra, pp. 66-86.

Santamarina, Antón (coord.) (2006-2013): Dicionario de Dicionarios. Corpus lexicográfico da lingua galega (dispoñíbel en: http://sli.uvigo.es/DdD/index.html). Vigo / Santiago de Compostela: Seminario de Lingüística Informática, Grupo TALG / Instituto da Lingua Galega. 